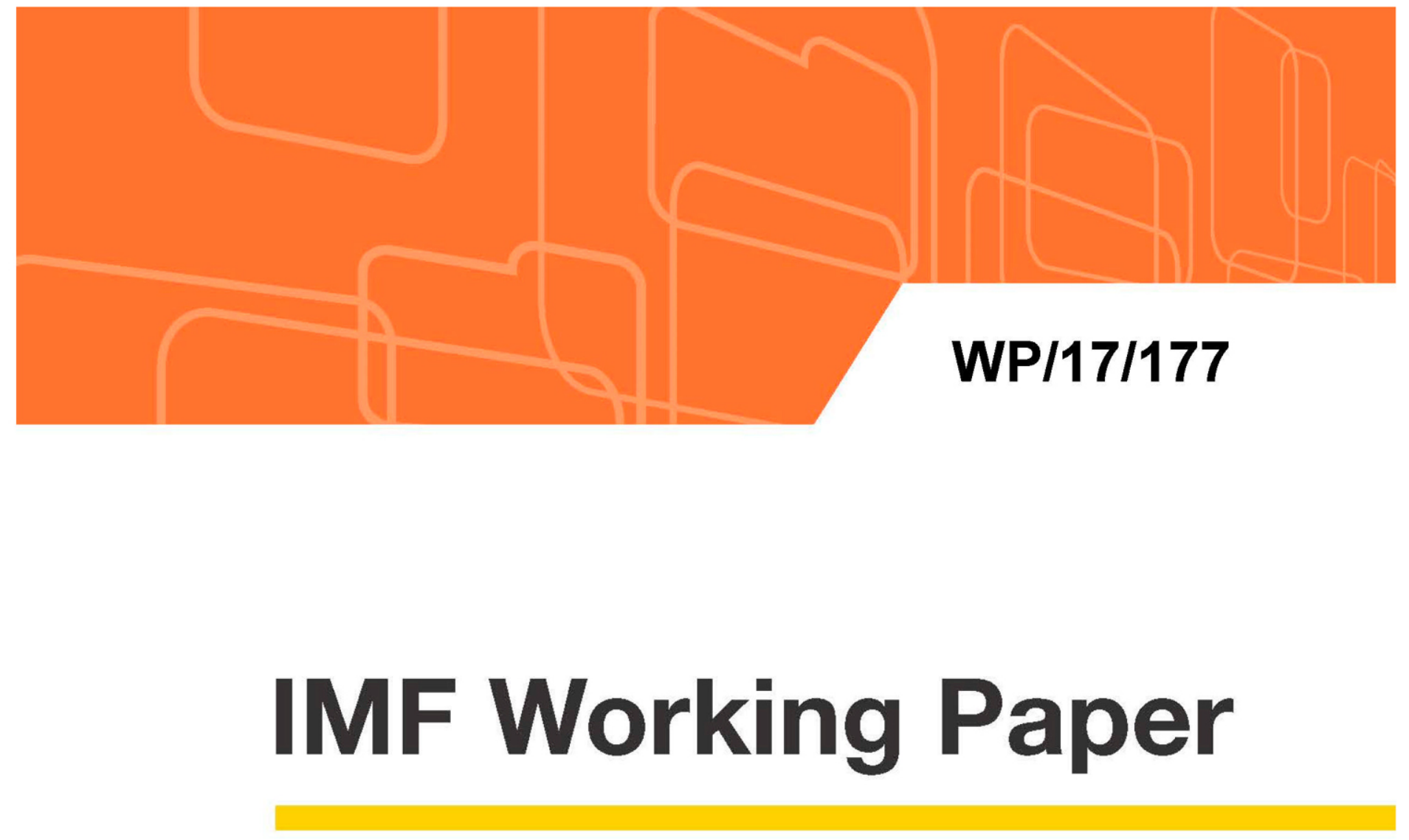

\title{
Mining Spillovers in Chile
}

by Esther Pérez Ruiz

IMF Working Papers describe research in progress by the author(s) and are published to elicit comments and to encourage debate. The views expressed in IMF

Working Papers are those of the author(s) and do not necessarily represent the views of the IMF, its Executive Board, or IMF management.

I N T E R N A T I O N A L M O N E T A R Y F U N D 


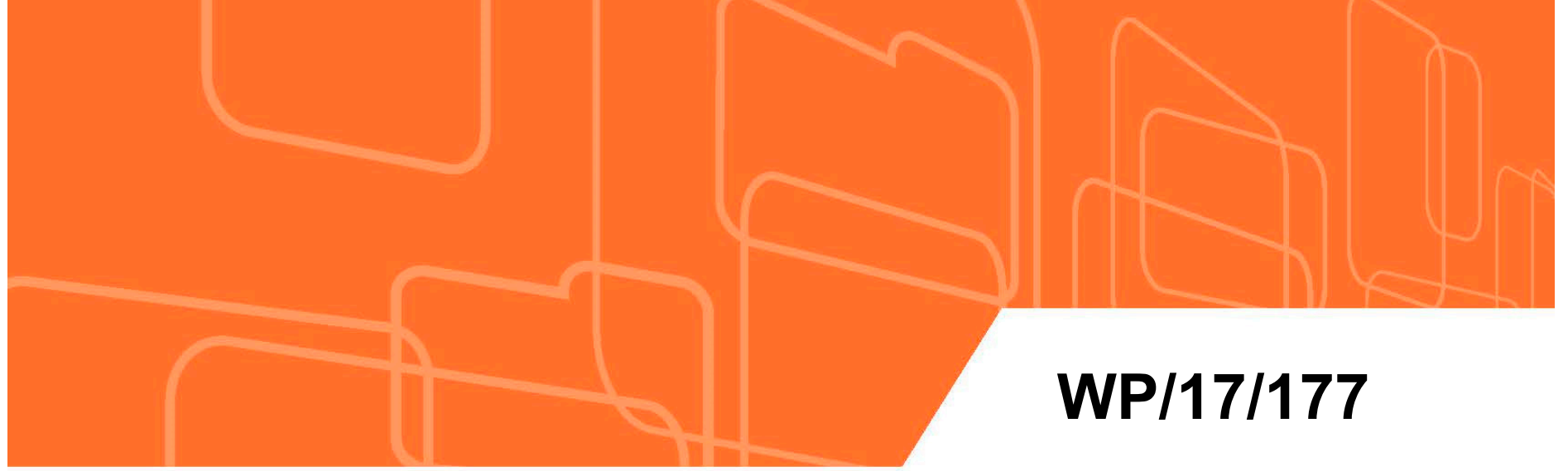

\section{IMF Working Paper}

\section{Mining Spillovers in Chile}

by Esther Pérez Ruiz

IMF Working Papers describe research in progress by the author(s) and are published to elicit comments and to encourage debate. The views expressed in IMF

Working Papers are those of the author(s) and do not necessarily represent the views of the IMF, its Executive Board, or IMF management.

I N T E R N A T I O N A L M O N E T A R Y F U N D 


\title{
IMF Working Paper
}

Western Hemisphere Department

\section{Mining Spillovers in Chile}

Prepared by Esther Pérez Ruiz

Authorized for distribution by Stephan Danninger

July 2017

\section{This Working Paper should not be reported as representing the views of the IMF.}

The views expressed in this Working Paper are those of the author(s) and do not necessarily represent those of the IMF or IMF policy. Working Papers describe research in progress by the author(s) and are published to elicit comments and to further debate.

\begin{abstract}
Chile's small open economy with significant mismatch between the production and consumption baskets may be represented by three stylized sectors, a commodity sector, a non-commodity tradable sector, and a non-tradable sector. This paper estimates the effect of copper price shocks on mining, manufacturing, and construction - each embodying a sector type. The empirical findings are for positive spillovers from mining to the other two sectors. However, the estimated size of the spillovers seems modest, which raises the question of the potential for mining to be better integrated with the rest of the economy.
\end{abstract}

JEL classification: E00, E30, F20, R11, R12

Keywords: Sectoral production, Output spillovers, Chile

Authors' contact information: eperezruiz@imf.org 


\section{CONTENTS}

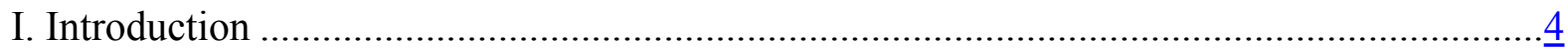

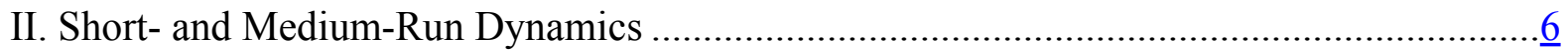

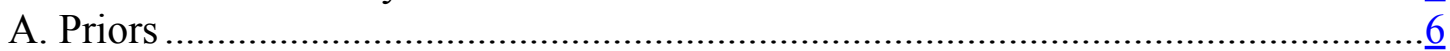

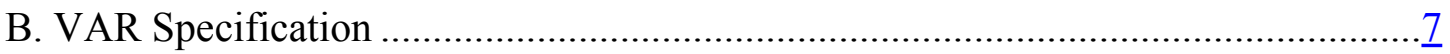

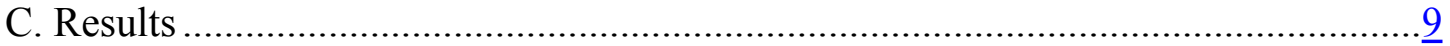

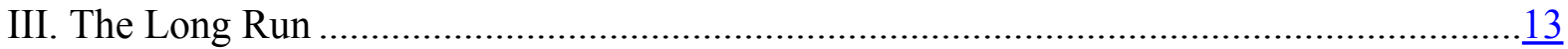

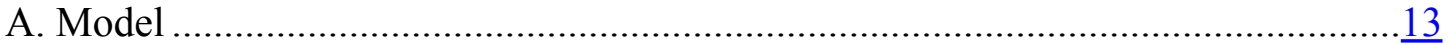

B. Empirical Specification.......................................................................

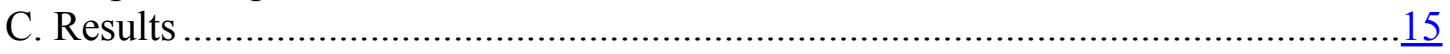

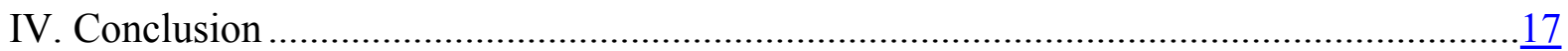

Figures

1. Chile: Output Impact of Copper Price, Shocks........................................................

2. Chile: Sectoral Production, Employment, and Productivity ….................................... 16

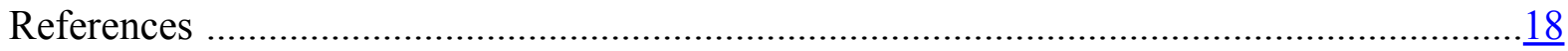


"Una economía como la chilena requiere viento de cola, como un mejor precio del cobre que impulsa la minería y rebalsa a otros sectores"

Dante Contreras, Departamento de Economía de la Universidad de Chile

Economía y Dinero, February 6, 2017

\section{INTRODUCTION ${ }^{1}$}

Mining cycles in Chile: which role for production spillovers? There is ample evidence documenting Chile's dependence of copper, which jointly with rapid growth in Asia over the past decade, has greatly benefitted the Chilean economy. Increased demand for copper typically leads to a positive terms of trade shock, boosting mining investment, output and real incomes in Chile. However, the benefits of increased commodity prices are not borne equally by other sectors of the Chilean economy, as higher copper prices typically come along with a stronger currency, making the country's other products less competitiveness on the export market-a development dubbed as "Dutch disease" by the literature. This paper investigates the extent to which key non-mining sectors of the Chilean economy benefit from the commodities boom. Is there evidence of positive spillovers from mining to other sectors? Or, on the contrary, is there evidence of "Dutch disease"? The topic of how drawn-out spillovers are from a terms of trade shock has regained relevance in Chile after the long growth slump since 2012.

Chile's economic structure and exposure to commodity price shocks (Table 1). A small open economy, and with starkly different production and consumption baskets for tradable goods, the Chilean economy is significantly exposed to commodity price shocks. On the supply side, the production and exports baskets are tilted towards mining, farming and fisheries, and the processing of natural resources. On the demand side, firms and households import a significant part of their intermediate inputs, machinery and equipment, and durable goods. Other nontradable sectors, representing less than half of total demand and supply, share the usual characteristic of being mostly produced and demanded locally.

\footnotetext{
${ }^{1}$ I am grateful to Stephan Danninger for support and guidance and to Martin Sasson for excellent research assistance.
} 


\begin{tabular}{|c|c|c|c|}
\hline \multicolumn{4}{|c|}{$\begin{array}{l}\text { Table 1. Trade Exposure by Industry } \\
\text { (In percent) }\end{array}$} \\
\hline \multirow[b]{2}{*}{ Farming, fishing and forestry } & \multirow{2}{*}{$\begin{array}{l}\begin{array}{l}\text { Export share of } \\
\text { production } 1 /\end{array} \\
\end{array}$} & Imported input share 2/ & \multirow{2}{*}{$\frac{\text { Import penetration 3/ }}{8.57}$} \\
\hline & & 20.79 & \\
\hline Mining & 83.42 & 14.13 & 8.12 \\
\hline Manufacturing & 25.45 & 71.02 & 20.46 \\
\hline Electricity, gas and water supply & 0.23 & 37.96 & 14.05 \\
\hline Construction & 0.01 & 19.66 & 8.38 \\
\hline Trade, hotels and restaurants & 6.63 & 9.21 & 4.52 \\
\hline Transport and communications & 13.06 & 43.36 & 17.47 \\
\hline Financial intermediation services & 2.23 & 10.92 & 6.71 \\
\hline Real estate activities & 0.33 & 0.41 & 0.32 \\
\hline Business related activities & 2.60 & 3.68 & 2.50 \\
\hline Personal services & 5.55 & 3.00 & 2.11 \\
\hline Public administration & 0.40 & 9.32 & 6.39 \\
\hline \multicolumn{4}{|c|}{$\begin{array}{l}\text { Source: BCCh, Input output tables } 2013 . \\
1 \text { / Exports as a share of total supply of the industry (domestic output plus imports). } \\
2 \text { / Imported inputs as share of domestic production. }\end{array}$} \\
\hline
\end{tabular}

Limitations of the one-sector-one-good paradigm. The mismatch between the domestic demand and supply bundles make the one-sector-one-good paradigm particularly limited as a representation of the supply response of the economy to commodity shocks. Rather, the Chilean economy may be characterized by three stylized sectors, a tradable sector highly exposed to commodity (copper) price shocks, a non-commodity tradable sector, and a non-tradable sector with production predominantly directed towards the home market. The copper mining, manufacturing, and construction sectors (altogether accounting for almost 30 percent of Chile's GDP) respectively embody each sector type and are therefore the focus of this paper.

Main purpose. This paper's main goal is to investigate how production in the three stylized sectors relate to each other in response to a copper price shock. It addresses two main questions. In the short to medium run, do shocks originating from copper prices have any effect on production in manufacturing and construction alongside mining? In the longer run, to what extent fluctuations in the mining exporting sector influence the growth perspectives of the other two sectors? Prima facie, one would expect that there exist spillover effects, since the empirical literature for Chile finds that copper price shocks alter the real effective exchange rate [references] hence the relative prices of the goods produced in each sector.

Previous literature for Chile. Although there are a few studies that examine the impact of shocks to commodity prices on the Chilean economy (Fornero and Kirchner, 2014, Fornero, Kirchner and Yany, 2016, Garcia and Olea, 2015), the empirical literature on output spillovers remains scant. We therefore contribute to the literature by estimating the effects of copper price shocks into the manufacturing and construction sectors - our proxies for non-copper tradable and nontradable sectors, respectively. Specifically, we estimate a VAR using data spanning 1995-2016 and examine the short- to medium-term dynamics in gross value added in response to copper price shocks. For long-run purposes, a model à-la Blanchard and Quah (1989) is extended to two production sectors and its implications used as identifying assumptions on the long run behavior. 
Main findings. Three main results emerge from this study. First, large capital costs and long investment times prevent mining supply from responding quickly to a positive copper price shock, with output rising relative to baseline only after three years. Second, higher copper prices generate, over the short- to medium-term, positive spillovers to production in manufacturing (via cheaper imported investment goods and intermediate inputs) and construction (likely reflecting mining-related construction and second-round income effects). Third, in the long term, shocks originating in copper prices have permanent effects on growth in the other two sectors. Similar implications follow from a negative copper price shock under the assumption of linearity. In all, while results are indicative of positive linkages between mining, manufacturing, and construction activity, the estimated size of spillovers seems modest, which raises the question of the potential for mining to be better integrated with the rest of the economy.

Structure of the paper. Section II presents the theoretical priors, VAR specification, and results for the purpose of short- to medium-run analysis. Section III does likewise for long-run dynamics. Section IV concludes.

\section{SHORT- AND MEDIUM-RUn DYNAMICS}

\section{A. Priors}

Description of the economy. The whole economy can be divided into a non-tradable sector and a tradable sector. The non-tradable sector, which is represented in this study by construction, ${ }^{2}$ consists of those industries or activities with prices determined by domestic demand and supply. The tradable sector consists of export and import-competing industries with prices primarily determined in the world market. It comprises the mining sector and manufacturing - the locus of the Dutch disease problem.

Short- to medium-run. The short- to medium-run may be conceived as a period of time where copper price shocks alter the real effective exchange rate, hence the relative prices of the goods produced in each three sectors, in a way that reflects their different trade exposure.

Channels. Three main channels shape the response of the three sectors under study to a positive copper price shock.

Global demand effects. Higher copper prices will benefit the copper exporting industry, insofar as they reflect higher global demand for copper.

Expenditure switching effects. Much of the first-round effects of a copper price shock is through the real effective exchange rate. A positive copper price shock typically comes along with an appreciation of the real effective exchange rate, making domestically produced goods more expensive relative to foreign production. Hence it is expected that

\footnotetext{
${ }^{2}$ Ideally, the exercise should distinguish between mining-related construction (construction of mines, transporting inputs to, and taking extracted resources away from mines) and the rest of the construction, most notably residential construction. Mining-related construction represents about half of total construction (Cámara Chilena de la Construcción, 2016).
} 
those industries that are relatively more exposed to trade experience larger effects. Specifically, those industries with relatively high import penetration and/or import share stand to gain the most; and vice-versa. ${ }^{3}$

Domestic income effects. A positive copper price shock can be expected to bring about second-round income effects from higher employment and income in the positively affected mining industry, and, in presence of positive spillovers, manufacturing and construction too.

Overall effects on each of the three sectors considered. In all, global demand effects are unambiguously positive for the copper-exporting industry; expenditure switching is ambiguous for non-copper industries, since it hampers competitiveness but cheapens imported goods (lower costs of inputs resulting from an appreciation may or may not offset the contractionary impact of reduced export competitiveness); and domestic income effects are expected to be unambiguously positive for all three sectors, with the effect expected to be larger for domestic-oriented industries. The empirical analysis in Section II.B will shed light on the combined effect of these channels for all three sectors.

\section{B. VAR Specification}

VAR configuration. To quantify the overall effect of a copper price shock on different industries we consider a standard VAR model

$$
Y_{t}=c+\sum_{i=1}^{p} \Phi_{i} Y_{t-1}+\sum_{i=0}^{p} \Phi_{i} X_{t-1}+\varepsilon_{t}
$$

where $Y_{t}, X_{t}, c, \Phi_{i}$, and $\varepsilon_{t}$ respectively denote the vector of endogenous variables, the vector of exogenous variables, the vector of constants, the matrices of autoregressive coefficients, and the vector of white noise processes. The exogeneity block $X_{t}$ incorporates the small open economy assumption — standard in the VAR literature for Chile — whereby foreign variables do not respond to changes in domestic variables.

$Y_{t}$ is a vector of six endogenous variables intended to characterize the Chilean economy:

$$
Y_{t}=\left\{\operatorname{cop}_{t}, v a_{-i t}, v a_{i t}, p_{t}, i_{t}, \text { reer }_{t}\right\}
$$

\footnotetext{
${ }^{3}$ In linking with the Dutch disease literature for resource-rich economies such as Chile, the concern is that commodity booms may result in currency appreciation (through rise in commodity prices and/or capital inflows directed towards mining investment), thus weakening or even shrinking the performance of other tradable sectors in the economy. Dutch disease was a term used in the 1970s to refer to the Netherlands' uneven economy after natural gas deposits were discovered in the North Sea. The resulting rise in the country's currency was blamed for the demise of Dutch manufacturing.
} 
where $\operatorname{cop}_{t}, v a_{-i t}, v a_{i t}, p_{t}, i_{t}$, reert respectively denote real copper prices, ${ }^{4}$ real GVA excluding the GVA of industry $i$, real GVA of industry $i$, the consumer price index, the monetary policy rate, and the real effective exchange rate. In order to analyze the impact of commodity prices on individual industries more thoroughly nominal GVA $\left(n v a_{-i t}, n v a_{i t}\right)$ is used as a subsidiary measure in the place of real GVA.

$X_{t}$ is a vector of three exogenous variables meant to capture world economic conditions:

$$
X_{t}=\left\{w g d p_{t}, p_{t}^{f}, i^{U S_{t}}\right\}
$$

where $w g d p_{t}, p_{t} t_{\text {, and }} i^{U S_{t}}$ respectively denote world real GDP, the U.S. consumer price index, and the Fed funds target rate.

Data. The dataset comprises quarterly seasonally-adjusted ${ }^{5}$ series, spanning $1995-2016$ for the mining, manufacturing, and construction sectors. With the exception of the domestic and U.S. interest rates, all variables in (2)-(3) are log first differences to ensure stationarity, ${ }^{6}$ and enter the VAR with two lags. ${ }^{7}$ Each industry model is estimated separately.

Identification. Identification of the structural shocks is achieved via a Cholesky recursive scheme, whereby identified shocks contemporaneously affect their corresponding variables and those ordered at a later stage, but have no impact on variables that are ordered before. ${ }^{8}$ This implies that the most exogenous (endogenous) variables should be placed first (last) in the VAR. With this in mind, commodity prices are placed first, since it is assumed that none of the Chilean variables can contemporaneously influence world copper prices. $v a_{-i t}$ and $v a_{i t}$ are assumed to be contemporaneously affected by copper prices but $v a_{\text {-it }}$ is placed in front of $v a$ it since each industry comprises only a small fraction of the total economy and, as such, the rest of the economy will have flow on individual industries in the same quarter. $p_{t}$ comes next, the presumption being that prices respond contemporaneously to copper prices and Chilean domestic output and that changes in the monetary policy rate $i_{t}$ take time to influence consumption and investment

\footnotetext{
${ }^{4}$ We include copper prices in the endogenous block to reflect the usage of commodities as financial assets that adjust instantaneously to news in the remaining foreign variables, including interest rates. Copper price shocks are Therefore interpreted as capturing signals of future changes in world demand for commodities. This interpretation is in line with Frankel (2006, 2008a, 2008b).

${ }^{5}$ Series where seasonally-adjusted using the Census X-13 procedure where they were not available in seasonally adjusted form from the original source.

${ }^{6}$ The modelling approach presumes that the variables are $I(1)$ and not co-integrated. Co-integrating relations are formally tested for, using the trace and maximum eigenvalue texts, and suggest that all variables used in the VAR model are non-stationary in levels but first-difference stationary.

${ }^{7}$ Lag exclusion and lag length criteria (Schwarz, Akaike, and Hannan-Quinn), point to two to three lags. Including too many lags risks over parameterizing the model, and so we retain two lags for the sake of parsimony.

${ }^{8}$ Cholesky identification scheme attributes all the effect of any common component to the variable that comes first in the VAR system.
} 
decisions, hence to flow through to prices. The real effective exchange rate responds contemporaneously to all variables, responding quickly to all available information.

\section{Results}

This section centers on the responses of the industry variables copper prices shocks. The main findings, which are summarized below, are suggestive of positive mining spillovers to both manufacturing and construction.

Overall effects (Figure 1). The results show that a positive copper price shock generates, over the near- to medium-term, an expansion of total output and a real effective exchange rate appreciation. In the short term, currency appreciation follows from higher international copper prices; in the medium term, higher foreign capital flows into the sector and an upward adjustment in domestic demand from positive wealth effects also play a role. ${ }^{9}$ Inflation falls on impact on pass-through effects, but increasing demand generates inflationary pressures after some periods, triggering a tightening response of monetary policy.

Delayed response in mining output. A one percent point shock to copper prices results in a negative response of mining GVA on impact, reaching a low at almost 0.1 percentage points below the baseline two to three quarters after the shock, and remains negative for about three years. This is due to the cost of intermediate inputs increasing by more than the gross volume of output. Mines are often run at close to full capacity, and a sudden increase in copper prices encourages increased extraction of minerals. This pushes up average costs of production insofar as marginal deposits require more intermediate inputs per unit of output, as is the case for Chile's old mines (Blagrave and Santoro, 2016, and Aguirregabiria and Luengo, 2015). In addition, there is a significant lead time associated with investing in new production capacity such as new mine sites, hence an increase in copper prices does not lead to an increase in mining in the short term (Fornero and others, 2016).

\footnotetext{
${ }^{9}$ Although some of the higher spending goes to imports and to the remittance of dividends abroad (funds' outflow for Chile), there is still a net appreciation.
} 
Positive wealth effects. ${ }^{10}$ The evidence is for strong positive income effects, as suggested by the response of nominal GVA in mining over $1 \frac{1}{2}$ year horizon. This reflects an increase in mining profits and wages (text chart). These benefits spread to other sectors in the economy, directly through positive demand shifts for intermediate inputs and final goods and services; and, indirectly, through higher collection of copper-related taxes.

Construction response. Real (and nominal) GVA for the construction sector respond positively (at 95 percent confidence band) to a copper price shock, peaking at 0.05 percentage points relative to the baseline after $1 \frac{1}{2}$ years, and remaining positive over a couple of years. The construction industry is subject to very little export demand or import competition. The positive response in activity likely reflects the involvement of the construction sector in the creation of new mines as well as second-round income effects from higher copper prices, both on aggregate demand and through wage formation. There is indeed evidence that mining booms in Chile lead to a tight labor market for the low-skilled segment of the labor force, which tends to be concentrated on the mining, construction, and some services sectors (references here).

Manufacturing response. Manufacturing real (and nominal) GVA respond positively (at 95 percent confidence band), with the response being more marked than for construction activity - almost 0.1 percentage points relative to the baseline after $1 \frac{1}{2}$ years. On the one hand, a positive copper price shock increases the costs of production in certain manufacturing subsectors, for which copper and other commodities are intermediate inputs, and makes manufacturing exports less competitive abroad. On the other hand, given manufacturing comparatively high share of imported investment goods and intermediate inputs, a positive copper price shock and concurrent real effective exchange rate appreciation, has positive effects on firms' profits and investment decisions. In addition, certain manufacturing industries may face increased demand following copper price shocks as the construction sector increases output. In all, the positive effects dominate and manufacturing stands to gain from a booming mining cycle, thanks to the sharply reduced prices of imports (relative to the prices of domestic supply) following the appreciation.

${ }^{10}$ Further analysis on the response of wages and profits is contingent on sectoral data from the Central Bank of Chile. 
Mining positive spillovers. Altogether, results point to positive linkages between mining, manufacturing, and construction activities. However, the estimated positive spillovers seem modest in size, especially for the construction sector. A similar exercise for Australia - a natural benchmark for Chile given its similar sectoral specialization - points to negative spillovers both to manufacturing and construction overall (at a one year horizon). ${ }^{11}$

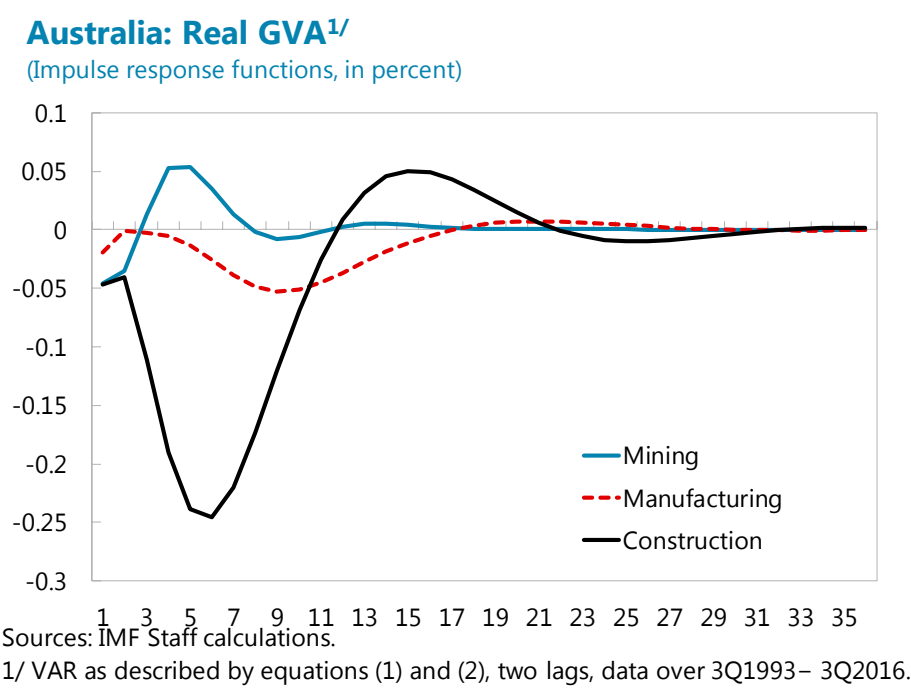

Caveats. The results presented here provide some indication of broad patterns of the Chilean economy to changes in copper prices and guidance about the relative importance of some of the main effects. There is, however, more certainty about magnitudes and the timing of responses. Even if the estimates IRFs accurately captured the response of the Chilean economy in the past, current relationships can be expected to evolve.

\footnotetext{
${ }^{11}$ For Australia, Bishop and others (2013) find negative spillovers from the resources sector to the other tradable sector (manufacturing, agriculture, transport, wholesale trade and accommodation, and food services) and nontradable (mostly comprising retail and non-mining related construction), and strong positive spillovers to miningrelated construction and business services industries.
} 
Figure 1. Chile: Output Impact of Copper Price Shocks
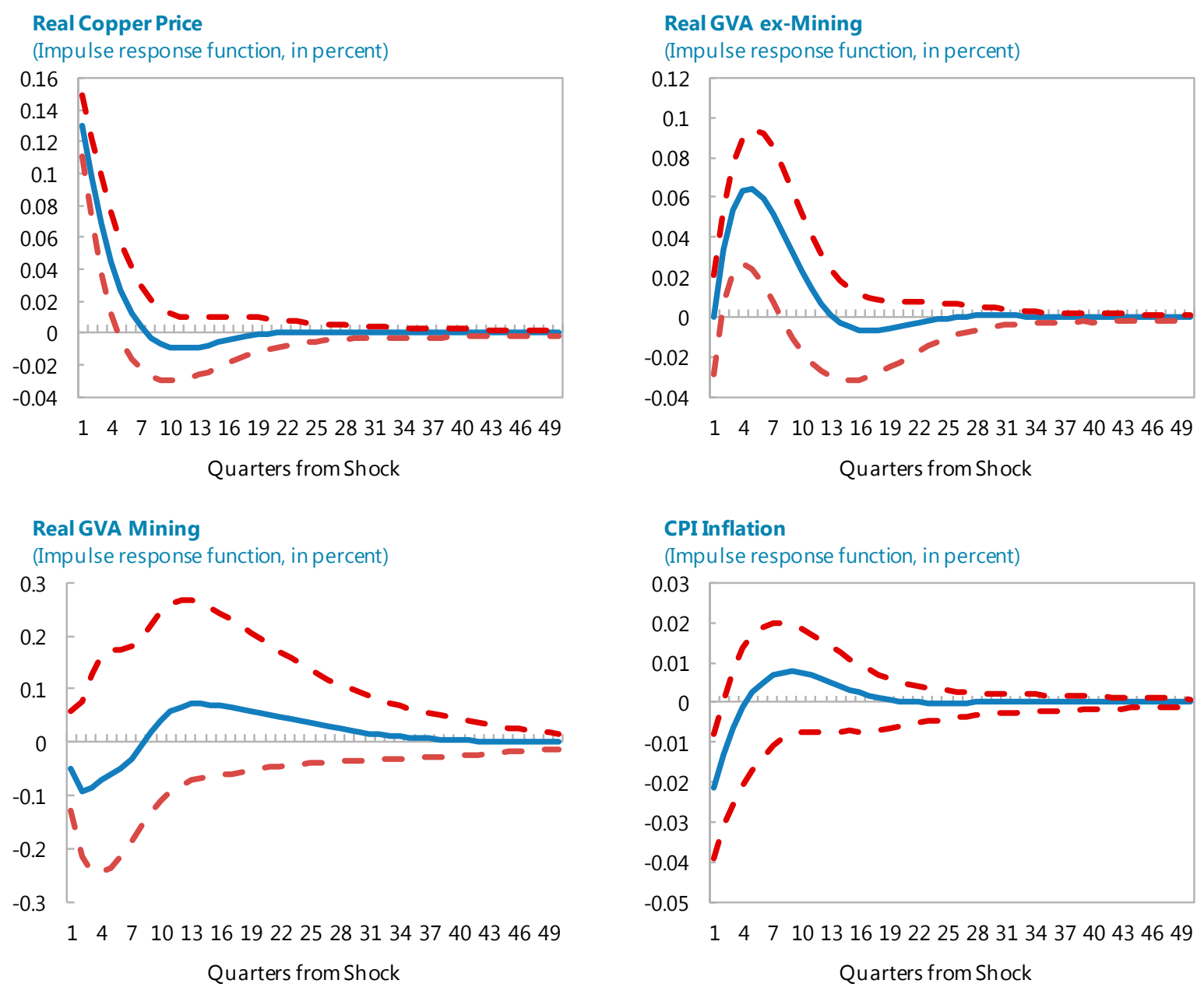

Monetary Policy Rate

(Impulse response function, in percent)

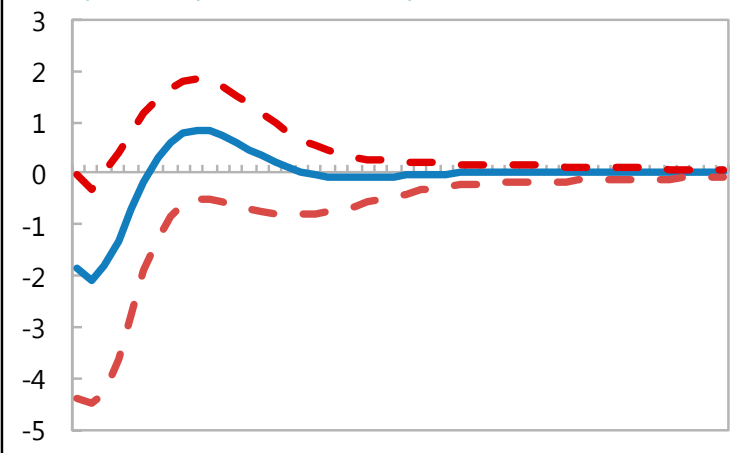

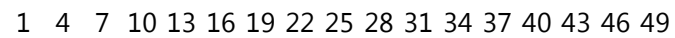

Quarters from Shock

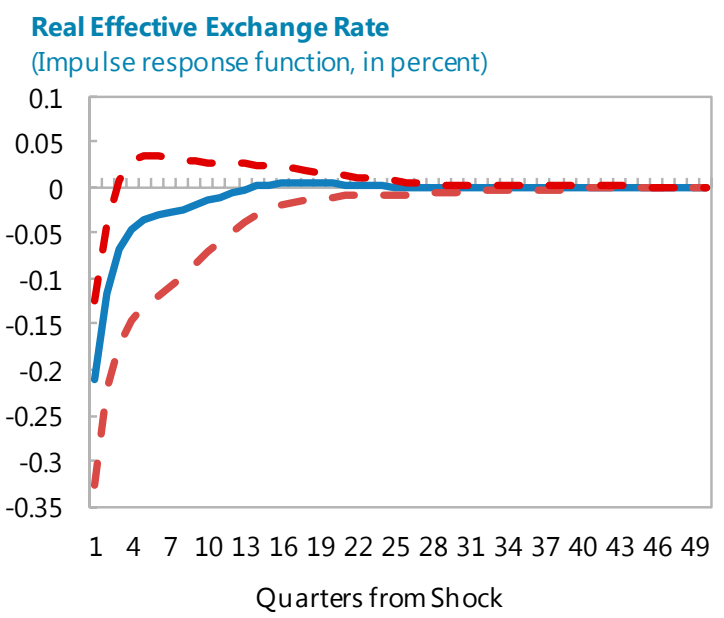

Source: IMF Staff calculations. 


\section{The Long RuN}

\section{A. Model}

Drawing on Fischer (1977) and Blanchard and Quah (1989), the model features the following equations:

$$
\begin{array}{rlrl}
y_{t}^{i} & =m_{t}-p_{t}^{i} & i=1,2 \\
y_{t}^{i}=\gamma^{i} n_{t}^{i}+\theta_{t}^{i} & i=1,2 \\
p_{t}^{i}=w_{t}^{i}-\theta_{t}^{i}+\left(1-\gamma^{i}\right) n_{t}^{i} & i=1,2 \\
w_{t}=w_{t}\left(E_{t-1} n_{t}=l_{t-1}\right) &
\end{array}
$$

The variables $y_{t, i}, p_{t, i}, w_{t, i}, n_{t, i}$, and $\theta_{t, i}$, are the (natural) logs of output, prices, nominal wages, employment, and the productivity level in each sector, respectively. The variables $m_{t}, w_{t}, n_{t}$ and $l_{t}$ denote the (natural) log of money supply, the aggregate nominal wage, employment in both sectors, and labor force, respectively.

Equation (4) is the demand for good $i$ implied by a Cobb-Douglas utility function. Equation (5) is the production function relating sectoral output to sectoral employment and productivity. Equation (6) is the zero-profit condition relating output prices to wages, productivity and employment. Equation (7) describes wage setting in the economy, whereby wages are set such that the expected total employment equals the labor force.

Exogenous variables labor force, sector specific productivity, and nominal money are assumed to follow each a random walk with drift:

$$
\begin{aligned}
& l_{t}=\mu^{l}+l_{t-1}+\varepsilon_{t}^{l} \\
& \theta_{t}^{i}=\mu^{i}+\theta_{t-1}^{i}+\varepsilon_{t}^{i} \quad i=1,2 \\
& m_{t}=\mu^{d}+m_{t-1}+\varepsilon_{t}^{d}
\end{aligned}
$$

where $\varepsilon_{t}^{l}, \varepsilon_{t}^{i}, \varepsilon_{t}^{d}$ respectively denote i.i.d. shocks to labor force, sector specific productivity and nominal demand.

Substituting (8)-(10) into (4)-(7) yields the following solution for overall employment and sectoral output:

$$
\begin{aligned}
& n_{t}=\varepsilon_{t}^{(d)}+\mu^{(l)} t+\sum_{j=1}^{t} \varepsilon_{t-j}^{(l)} \\
& y_{t}^{(i)}=\gamma^{(i)} \varepsilon_{t}^{(d)}+\gamma^{(i)}\left(\mu^{(l)}(t-1)+\sum_{j=1}^{t} \varepsilon_{t-j}^{(l)}\right)+\mu^{(i)} t+\sum_{j=0}^{t} \varepsilon_{j=o}^{(i)} \quad \mathrm{i}=1,2
\end{aligned}
$$

The proposed model implies that nominal money $\varepsilon_{t}^{d}$ has only short-run effects on production and employment. In the long run, employment follows the labor trend (equation 11), sectoral 
production follows both the sector-specific productivity trend and the labor trend (equation 11) ${ }^{12}$ and there is no spillover between the sectors. Long-run output spillovers would follow from an alternative parameterization of the production function allowing for substitution between goods. As far as spillovers is concerned, the empirical strategy laid out in this paper maintains the hypothesis of no spillovers from manufacturing or construction to mining, and tests the presence of spillovers from mining to the two other sectors (Section III.B).

\section{B. Empirical Specification}

Identification. Identification aims to identify three out of the four structural disturbances in the model, the labor force shock and the two sectoral productivity shocks. Thus, $\varepsilon_{t}^{l}, \varepsilon_{t}^{i}, \varepsilon_{t}^{d}$ would capture a mixture of supply and demand disturbances having permanent effects in the long-run. The structural VAR model used for identification is specified as: ${ }^{13}$

$$
B(L) \Delta x_{t}=\delta+\eta_{t}
$$

where $x t$ is a $3 x 1$ vector containing the endogenous variables, (the log of) employment and production in Sector 1 and 2, respectively, $x_{t}=\left[\begin{array}{lll}n_{t} & y_{t}^{1} & y_{t}^{2}\end{array}\right] . B(L)$ is a matrix polynomial in the lag operator of order $p, B(L)=I_{n}-\sum_{j=1}^{p} B_{j} L^{j}$, where $L^{j} z_{t}=z_{t-j}, \delta$ is a $3 x 1$ vector of constants, and $\eta_{t}$ is a vector of zero-mean, i.i.d. disturbances, and $E\left(\eta_{t} \eta_{t}^{\prime}\right)=\Sigma$, a positive definite matrix.

Assuming that the structural disturbances are linearly related to the reduced-form forecasting errors, $\eta_{t}=C \varepsilon_{t}$, and using a Wold representation to relate the endogenous and exogenous variables of the system, it is possible to express the levels of the endogenous variables as:

$$
x_{t}=D(1) \tau_{t}+D^{*}(L) \varepsilon_{t}
$$

where the coefficients of the $D(1)$ matrix measure the long run effects from the permanent shocks to the trend in $\tau_{t}=\left[\begin{array}{lll}1_{t} & \theta_{t}^{1} & \theta_{t}^{2}\end{array}\right]^{\prime}$.

Exact identification can be achieved by imposing three zero restrictions on the long-run responses to the shocks:

$$
D(1)=\left[\begin{array}{ccc}
d_{11} & 0 & 0 \\
d_{21} & d_{22} & 0 \\
d_{31} & d_{32} & d_{33}
\end{array}\right]
$$

\footnotetext{
${ }^{12}$ A system including only sectoral production would find spurious evidence of spillovers in both directions. Incorporating employment to the model allows to distinguish between sector-specific productivity shocks and common labor force shocks.

${ }^{13}$ A VAR in differences is appropriate since all production and employment variables considered in the empirical analysis are found to be I(1) variables but not co-integrated.
} 
The identification strategy embedded in (12) assumes that (i) in the long run, the common labor force trend and the sector-specific productivity trends drive production in each sector $\left(d(1)_{21} \neq 0\right.$, $d(1)_{22} \neq 0, d(1)_{31} \neq 0 d(1)_{33} \neq 0$ ); (ii) employment is driven by the labor force $\left(d(1)_{12}=0, d(1)_{13}\right.$ $=0)$; (iii) the sector-specific trend in manufacturing (construction) has no long-run effect on production in mining, $d(1)_{23}=0$, as the evidence seems to support (see, for instance, Correa Mautz, 2016). Given (i), (ii), and (iii) we test whether there are long-run spillovers from mining to manufacturing (construction), that is, whether $d(1)_{32} \neq 0$.

The data (Figure 4). The dataset comprises quarterly seasonally-adjusted ${ }^{14}$ series, spanning 1990-2016 for mining and manufacturing sectors, and 1996-2016 for the construction sector. Value added and employment are National Accounts (NA) data and labor force is taken from the Labor Force Survey. For mining and manufacturing, industrial production is also considered as an alternative to the NA source. ${ }^{15}$ All variables are in (natural) logarithms and enter the VAR with two lags. ${ }^{16}$

\section{Results}

Positive mining spillovers. The results indicate that there are positive spillovers between mining and manufacturing, and between mining and construction. We can then conclude that growth in manufacturing and construction positively depends on growth in the other sector in the long run. Furthermore, all other coefficients are significantly different from zero and they have the expected sign: sectoral shocks significantly affect production in that same sector and shocks to the labor trend are found to be a

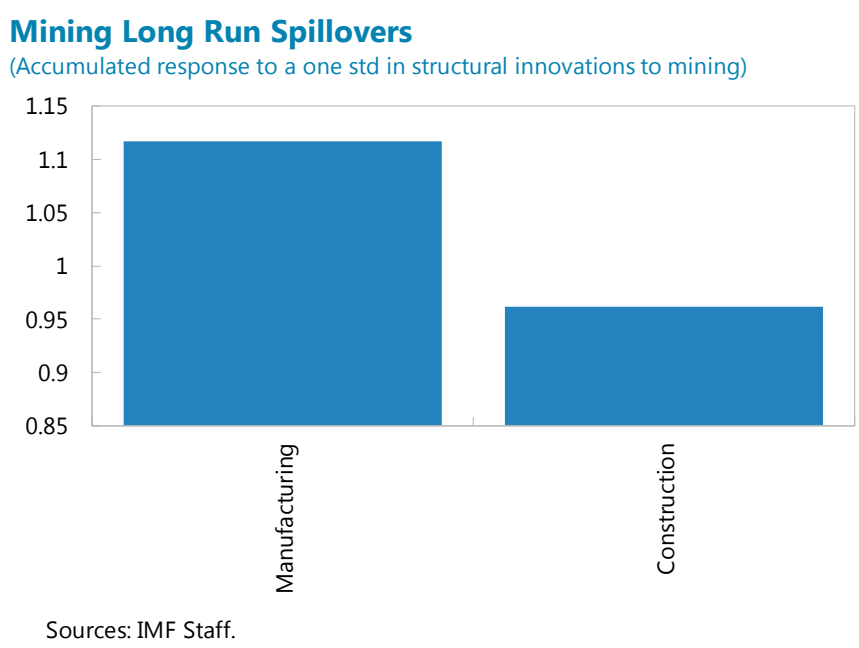
common source of fluctuations.

\footnotetext{
${ }^{14}$ Series where seasonally-adjusted using the Census X-13 procedure where they were not available in seasonally adjusted form from the original source.

${ }^{15}$ Results are almost identical by the two alternative data sources.

${ }^{16}$ The lag structure of the VAR is determined by means of lag exclusion and lag length criteria.
} 


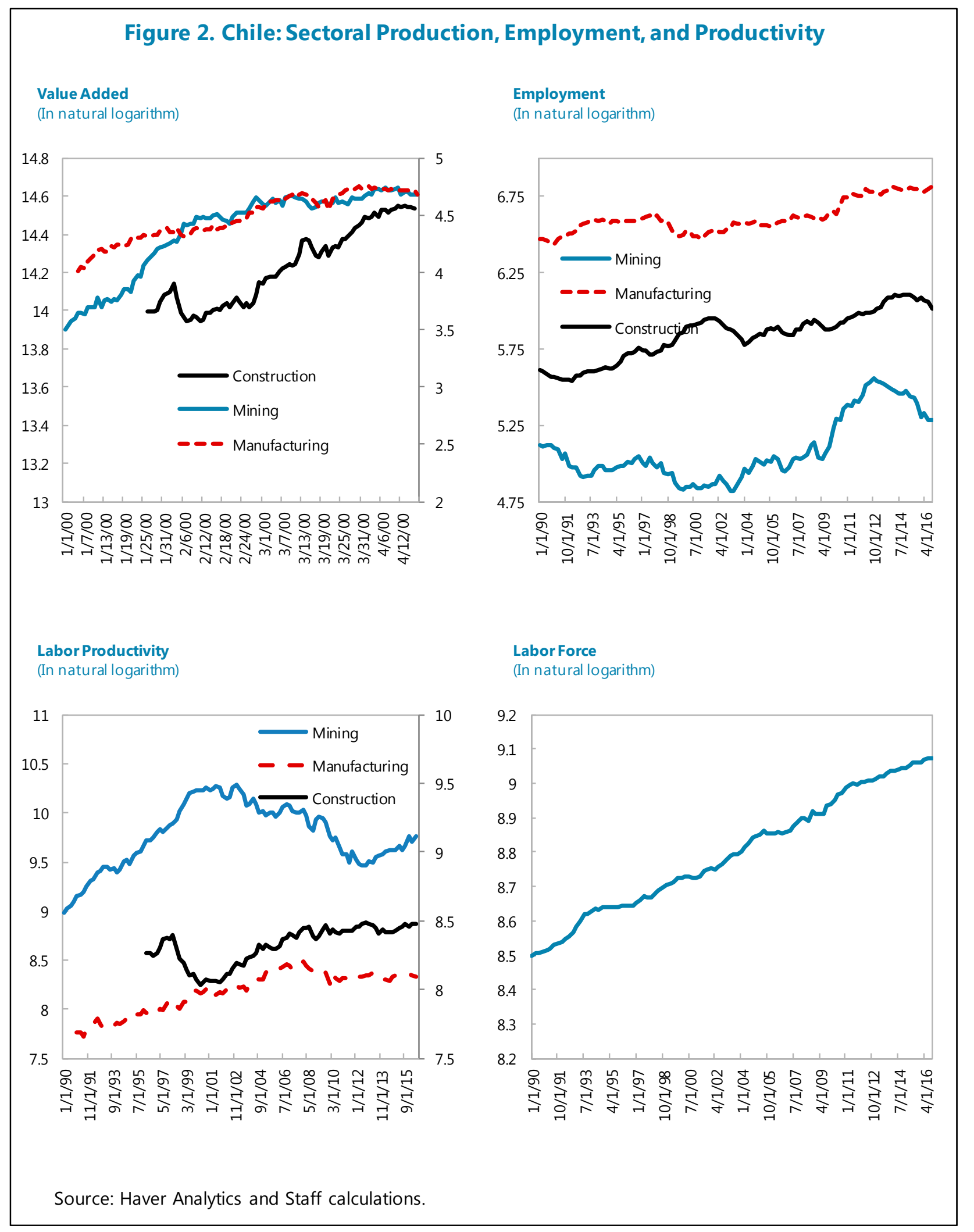

CInternational Monetary Fund. Not for Redistribution 


\section{Conclusion}

Motivation. Chile has experienced several copper price boom episodes greatly benefiting the resource sector via a surge of capital inflows and higher investment and incomes. An important question is how fluctuations in mining activity spillover to other sectors. Do all parts of the economy benefit? To what extent non-resource related sectors experience a reduction in competitiveness due to the exchange rate appreciation - a development dubbed in the literature as "Dutch disease"?

Key findings. Over 1995-2016, VAR analysis suggests that a 1 percent increase in real copper prices increases mining output over the medium term, generating positive spillovers into manufacturing and construction activities. In the long run, it is found that permanent shocks originating in mining have a positive effect on manufacturing and construction, and that shocks to the labor trend are a common source of fluctuations in sectoral production. Altogether, results seem to reject the "Dutch disease" hypothesis and rather point to positive linkages between mining, manufacturing, and construction activities. However, the estimated size of the spillovers seems modest, which raises the question of the potential for mining to be better integrated with the rest of the economy.

Policy implications. Chile is a world leader for copper production and, as of 2016, the mining sector still accounts for around 10 percent of GDP, originates half of the exports, and represents 30 percent of investment. Moreover, this paper finds evidence of positive spillovers to two other major sectors in Chile, manufacturing and construction. However, the size of the spillovers is estimated to be modest, suggesting that there is room for mining to generate stronger linkages to the rest of the economy, particularly to manufacturing (processing of copper and other highvalue added mining products). Moreover, to the extent that the mining sector continues to play an important role in Chile's production mix, the findings in this paper also point to the need of promoting the competitiveness in other tradable sectors such as manufacturing, and more broadly, agriculture or tourism, to help avoid, or mitigate, Dutch disease effects. 


\section{REFERENCES}

Blanchard, O.J., and Quah, D., 1989, “The Dynamic Effects of Aggregate Demand and Supply Disturbances”, The American Economic Review, Vol. 79, No. 4, pp. 654-673.

Aguirregabiria, V., and A. Luengo, 2015, “A Microeconometric Dynamic Structural Model of Copper Mining decisions," http://boston.eventful.com/events/microeconometricdynamic-structural-model-copp-/E0-001-073746375-3

Blagrave, P., and M. Santoro, 2016, "Estimating Potential Output in Chile: A Multivariate Filter for Mining and Non-Mining Sectors," IMF Working Paper No. 16/201 (Washington: International Monetary Fund).

Bishop, J., C. Kent, M. Plumb and V. Rayner, 2013, “The Resources Boom and Australian Economy: A Sectoral Analysis,” RBA Bulletin, (March), pp. 39-49.

Correa Mautz, F., 2016, "Encadenamientos productivos desde la mineria de Chile," Serie Desarrollo Productivo, 203, CEPAL, Naciones Unidas.

Fornero, J., and M. Kirchner, 2014, "Learning About Commodity Cycles and Saving- Investment Dynamics in a Commodity-Exporting Economy," Working Papers No. 727, Central Bank of Chile.

Fornero, J., M. Kirchner and A. Yany, 2016, "Terms of Trade Shocks and Investment in Commodity-Exporting Economies,” Working Papers No. 773, Central Bank of Chile.

Frankel, J.A., 2006, “The Effect of Monetary Policy on Real Commodity Prices,” NBER Working Papers 12713,( National Bureau of Economic Researh, Inc). , 2008a, “An Explanation for Soaring Commodity Prices,"
$\underline{\text { http://www.voxeu.org/index.php?q=node/1002 }}$

- 2008b, "Fed Modesty Regarding Its Role in High Commodity Prices," http://content.ksg.harvard.edu/blog/jeff frankels weblog/category/commodities

García, P., and S. Olea, 2015, "Inversión Minera y Ajuste Macroeconómico en Australia y Chile," Economic Policy Papers No. 56, Central Bank of Chile.

Knop, S. J., and J.L. Vespignani, “The Sectorial Impact of Commodity Price Shocks in Australia," Discussion Paper Series N 2014-05, Tasmanian School of Business and Economics, Australia. 